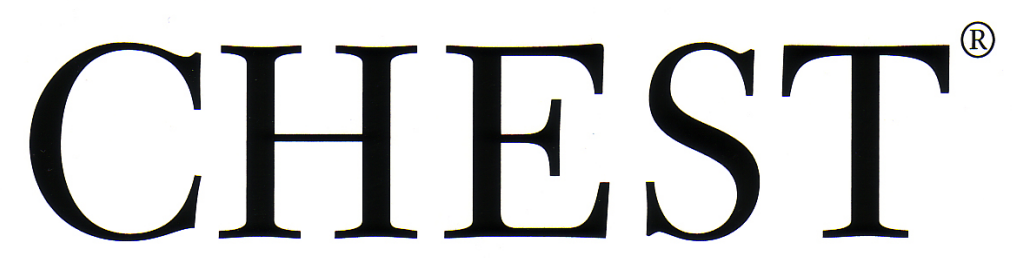

THE CARDIOPULMONARY

AND CRITICAL CARE JOURNAL

FOR PULMONOLOGISTS, CARDIOLOGISTS, CARDIOTHORACIC SURGEONS, CRITICAL CARE PHYSICIANS, AND RELATED SPECIALISTS

\title{
Efficacy of Bosentan in a Small Cohort of Adult Patients With Pulmonary Arterial Hypertension Related to Congenital Heart Disease
}

Raymond L. Benza, Barry K. Rayburn, Jose A. Tallaj, Christopher S. Coffey, Laura J. Pinderski, Salpy V. Pamoukian and Robert C. Bourge Chest 2006;129;1009-1015

DOI: $10.1378 /$ chest.129.4.1009

\section{This information is current as of April 12, 2006}

The online version of this article, along with updated information and services, is located on the World Wide Web at:

http://www.chestjournal.org/cgi/content/full/129/4/1009

CHEST is the official journal of the American College of Chest Physicians. It has been published monthly since 1935. Copyright 2005 by the American College of Chest Physicians, 3300 Dundee Road, Northbrook IL 60062. All rights reserved. No part of this article or PDF may be reproduced or distributed without the prior written permission of the copyright holder. ISSN: 0012-3692.

\section{A M E R I C A C O L L E G E O F}

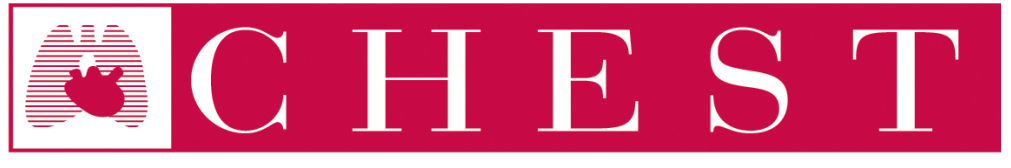

$\begin{array}{llllllllll}\mathrm{P} & \mathrm{H} & \mathrm{Y} & \mathrm{S} & \mathrm{I} & \mathrm{C} & \mathrm{I} & \mathrm{A} & \mathrm{N} & \mathrm{S}\end{array}$




\title{
Efficacy of Bosentan in a Small Cohort of Adult Patients With Pulmonary Arterial Hypertension Related to Congenital Heart Disease*
}

\author{
Raymond L. Benza, MD; Barry K. Rayburn, MD; Jose A. Tallaj, MD; \\ Christopher S. Coffey, PhD; Laura J. Pinderski, MD, PhD; \\ Salpy V. Pamoukian, MD; and Robert C. Bourge, MD
}

\begin{abstract}
Objectives: This study was designed to assess the tolerability and efficacy of the oral endothelin receptor antagonist bosentan in adult patients with pulmonary arterial hypertension (PAH) related to congenital heart disease (CHD).

Background: Severe PAH in the setting of CHD is a debilitating syndrome for which there are limited treatment options. This is the first long-term study experience in adults reporting on the tolerability and efficacy of therapy with bosentan for this patient population.

Methods: A 12-month single-center experience with 19 women and 5 men with PAH associated with CHD (79\% in New York Heart Association [NYHA] class III) was analyzed. Hemodynamic responses, exercise capacity, and Borg dyspnea index were assessed prior to the administration of bosentan, and again at 3, 6, and 12 months after the study began. Clinical assessments were performed monthly for up to 12 months. The change from baseline was tested using the Wilcoxon pairs test.

Results: There was significant improvement in hemodynamics from baseline to 12 months (mean [ \pm SD] systolic pulmonary arterial pressure, $99 \pm 30$ to $87 \pm 28 \mathrm{~mm} \mathrm{Hg}[\mathrm{p} \leq 0.001]$; mean pulmonary arterial pressure, $60 \pm 18$ to $52 \pm 17 \mathrm{~mm} \mathrm{Hg}[\mathrm{p} \leq 0.001$ ]; mean right atrial pressure, $12 \pm 6$ to $8 \pm 5 \mathrm{~mm} \mathrm{Hg}[\mathrm{p} \leq 0.001]$; mean pulmonary vascular resistance, $663 \pm 386$ to $504 \pm 307$ dyne $\cdot \mathrm{s} \cdot \mathrm{cm}^{-5}[\mathrm{p}<0.01]$; pulmonary capillary wedge pressure, $15 \pm 5$ to $11 \pm 3 \mathrm{~mm} \mathrm{Hg}$ [p < 0.001]). NYHA functional class also improved from baseline to 12 months (NYHA class I/II range, 17 to $71 \% ; p<0.001)$. There was a marginally significant trend toward improvement in the mean 6-min walk test distance at 12 months $(299 \pm 85$ to $330 \pm 95 \mathrm{~m} ; \mathrm{p}=0.05)$. Three patients needed to discontinue bosentan therapy because of elevated liver function test results. There were no deaths or hospitalizations, and no significant change in arterial oxygen saturation had occurred at 12 months.

Conclusions: Bosentan therapy improved hemodynamics and NYHA class in patients with PAH that was associated with CHD. These effects were seen after 3 to 6 months. Bosentan therapy may provide an effective alternative to current therapies in this patient population.
\end{abstract}

(CHEST 2006; 129:1009-1015)

Key words: bosentan; congenital heart defects; endothelin; pulmonary hypertension

Abbreviations: $\mathrm{CHD}=$ congenital heart disease; $\mathrm{CI}=$ cardiac index; $\mathrm{ET}=$ endothelin; $\mathrm{LFT}=$ liver function test; $\mathrm{mPAP}=$ mean pulmonary arterial pressure; NYHA $=$ New York Heart Association; PAH $=$ pulmonary arterial hypertension; $\mathrm{PVR}=$ pulmonary vascular resistance; $\mathrm{RAP}=$ right atrial pressure; $\mathrm{sPAP}=$ systolic pulmonary arterial pressure
A
progressive and severe form of pulmonary arte- rial hypertension $(\mathrm{PAH})$ can affect approximately $8 \%$ of individuals with congenital heart disease (CHD) and $11 \%$ with left-to-right intracardiac

shunting. ${ }^{1}$ While some patients may survive 20 to 30 years after receiving the diagnosis, ${ }^{2}$ they can experience a significant reduction in functional capacity and quality of life due to the progressive nature of 
their PAH. ${ }^{3}$ In addition, those patients with Eisenmenger physiology have a substantial risk of pulmonary artery thrombus formation. ${ }^{4}$

Historically, the treatment options for these patients were limited. In patients with established PAH, particularly those with Eisenmenger syndrome, attempts at surgical closure of systemic-topulmonary connections can, in fact, increase the risk of death..$^{5}$ Numerous drawbacks also exist with lung or heart/lung transplantation, ${ }^{6,7}$ including scarcity of organs and high mortality rates. Advances in nonsurgical therapy for this disease, including treatment with the vasodilators epoprostenol and its analog treprostinil, are now being reported in the literature. ${ }^{8,9}$ While effective, several distinct disadvantages exist with these forms of therapy, which limit their generalized use, stressing the need for alternative treatments. ${ }^{3}$

One additional therapy that has been approved for the treatment of $\mathrm{PAH}$ is endothelin (ET) receptor antagonism. ET-1, which is a mitogen and a potent vasoconstrictor that is produced by vascular endothelial and smooth muscle cells, plays a central role in the pathogenesis of several cardiovascular diseases, including PAH. Significant elevations in ET-1 levels are noted in patients with various forms of $\mathrm{PAH},{ }^{10}$ including those with Eisenmenger syndrome. ${ }^{11}$ Moreover, this increased plasma concentration of the ET-1 peptide seems to be directly related to the severity of pulmonary hypertension in patients with and without congenital heart defects. ${ }^{11,12}$

Bosentan, a nonpeptide ET receptor antagonist, is an orally approved therapy for the treatment of PAH. ${ }^{13}$ It is a specific and competitive antagonist that not only acts as a vasodilator, but also blocks the proinflammatory, ${ }^{14}$ hypertrophic, ${ }^{15}$ and profibrotic ${ }^{16}$ effects of ET-1.3 Importantly, bosentan was also noted to significantly improve functional capacity and pulmonary vascular resistance (PVR) in adults with several forms of $\mathrm{PAH},{ }^{17}$ while avoiding the risks associated with continuous IV administration. Several reports ${ }^{18}$ have now noted short-term improvements in functional class in patients with $\mathrm{PAH}$ related to CHD using bosentan. However, reports

${ }^{\star}$ From the Departments of Medicine (Drs. Benza, Rayburn, Tallaj, Pinderski, Pamoukian, and Bourge) and Biostatistics (Dr. Coffey), University of Alabama at Birmingham, Birmingham, AL. This work was not supported by any external funding.

Manuscript received November 30, 2004; revision accepted October 7, 2005.

Reproduction of this article is prohibited without written permission from the American College of Chest Physicians (www.chestjournal. org/misc/reprints.shtml).

Correspondence to: Raymond L. Benza, MD, Tinsley Harrison Towers, Room 328A, 1900 University Blvd, Birmingham, AL 35294-0006; e-mail: rbenza@uab.edu studying the long-term efficacy of bosentan in this class of patient are lacking. We report in this article on our single-center experience of the long-term (ie, 12 months) tolerability and efficacy of bosentan in adult patients with PAH that is related to congenital heart defects.

\section{Materials AND Methods}

All patients described in this study were followed up in the Pulmonary Vascular Disease Clinic at the University of Alabama at Birmingham and have received a diagnosis of PAH associated with CHD. This diagnosis was made utilizing World Health Organization criteria after an extensive search for other secondary causes for pulmonary hypertension. Adult patients currently receiving either epoprostenol or treprostinil were considered to be eligible for treatment if they were persistently classified as being in New York Heart Association (NYHA) functional class III or worse or were in NYHA functional class II and experiencing major side effects from prostacyclin-based therapy that necessitated a dose reduction. All data reported in this study were collected per our routine clinical practice. The University of Alabama at Birmingham Institutional Review Board approved the anonymous collection and analysis of data obtained clinically.

Baseline information including demographic data, duration of diagnosis, current medical therapy, and clinical characteristics prior to the initiation of bosentan therapy was available for all patients. Baseline hemodynamic and echocardiographic data on the patient's current medical regimen were available and had been collected within 30 days prior to the initiation of bosentan therapy in all patients.

Bosentan therapy was initiated at a dose of $62.5 \mathrm{mg}$ bid with a planned increase to $125 \mathrm{mg}$ bid at 1 month from the initiation of therapy. Therapy was initiated in patients with open shunts or systemic systolic BP at $<100 \mathrm{~mm} \mathrm{Hg}$ at $31.25 \mathrm{mg}$ bid, with a planned increase to $62.5 \mathrm{mg}$ bid in 2 weeks, and to $125 \mathrm{mg}$ bid by 4 weeks. Patients were seen thereafter on a monthly basis or sooner, as indicated by their clinical status. At each visit, data were collected including current medications, NYHA functional class, 6-min walk distance test, Borg dyspnea index at completion of walk test, potential side effects of therapy, resting and exercise peripheral oxygen saturation, weight, vital signs, and laboratory parameters, including electrolyte levels and liver function test (LFT) results. To assess the clinical efficacy of therapy and the volume status of each patient, a right-heart catheterization and two-dimensional echocardiography were performed at 3,6, and 12 months after the initiation of bosentan therapy. Cardiac output measurements were made using the Fick methodology. Prostacyclin doses were held constant during the 12 months of observation unless patients were experiencing intolerable side effects from prostacyclin.

The data were presented as mean values and SDs. Data analysis was performed utilizing statistical software packages (Statistica; StatSoft; Tulsa, OK; and SAS, version 9.0; SAS Institute; Cary, NC). The difference between time points for continuous variables was tested using the Wilcoxon pairs test. Among the subset of patients who changed with regards to NYHA functional class over the course of the study, the McNemar $\chi^{2}$ test was used to test whether patients were more likely to improve than would be expected by chance. An intention-to-treat model was used. All available data points, provided that the subject provided a baseline and at least one follow-up measurement, were analyzed, including those of patients who withdrew from bosentan therapy. In the case of missing data, the latest available data point was carried forward. 


\section{RESUlts}

\section{Patient Disposition}

Twenty-four adults (19 female, 5 male; mean age, $50 \pm 13$ years) with primary pulmonary hypertension and other forms of PAH were started on therapy with bosentan. At the start of the study, all participants were in NYHA functional classes II through IV, with a majority (79\%) in class III. Eight patients (33\%) were being treated with a prostacyclin analog, treprostinil (mean dose, $28.4 \mathrm{ng} / \mathrm{kg} / \mathrm{min}$ ) for a mean duration of $864 \pm 317$ days. No patients were treated with epoprostenol during the course of the study. The baseline characteristics of the patient population enrolled in the study are presented in Table 1 . The percentage of patients receiving 250 $\mathrm{mg} / \mathrm{d}$ bosentan was $79 \%$ at 3 months, $83 \%$ at 6 months, and $79 \%$ at 12 months. At the end of the 12-month treatment period, 19 participants received $250 \mathrm{mg} / \mathrm{d}, 1$ participant received $187.5 \mathrm{mg} / \mathrm{d}, 3$ participants discontinued receiving the drug because of elevated LFT values, and 1 participant was lost to follow-up after 9 months.

\section{Cardiopulmonary Hemodynamics}

Due to the lack of complete catheterization data, three subjects were excluded from all hemodynamic comparisons. Two patients refused catheterizations, and one patient had undergone only a baseline study. The means, SDs, and results comparing changes

Table 1-Baseline Clinical Characteristics of Participants*

\begin{tabular}{|c|c|}
\hline Characteristics & Values \\
\hline Study group & 24 \\
\hline Age, yr & $50 \pm 13$ \\
\hline White race & $20(83)$ \\
\hline Female gender & $19(79)$ \\
\hline \multicolumn{2}{|l|}{ Defect type } \\
\hline ASD & $14(58)$ \\
\hline VSD & $4(17)$ \\
\hline Complex congenital & $6(25)$ \\
\hline \multicolumn{2}{|l|}{ Shunt patency } \\
\hline Open & $19(79)$ \\
\hline Closed & $5(21)$ \\
\hline \multicolumn{2}{|l|}{ NYHA functional class } \\
\hline II & $4(17)$ \\
\hline III & $19(79)$ \\
\hline IV & $1(4)$ \\
\hline \multicolumn{2}{|l|}{ Prostacyclin exposure } \\
\hline Treprostinil & $8(33)$ \\
\hline Epoprostenol & $0(0)$ \\
\hline \multicolumn{2}{|l|}{ Baseline prostacyclin dose } \\
\hline Treprostinil, ng/kg/min & 28.4 \\
\hline Epoprostenol & NA \\
\hline
\end{tabular}

from baseline for the various hemodynamic measurements are shown in Figure 1 and Table 2. After 12 months of treatment, significant decreases from baseline values were seen in systolic pulmonary arterial pressure (sPAP) [from $99 \pm 30$ to $87 \pm 28$ $\mathrm{mm}$ Hg; $\mathrm{p}<0.001$ ], mean pulmonary arterial pressure (mPAP) $[60 \pm 18$ to $52 \pm 17 \mathrm{~mm} \mathrm{Hg} ; \mathrm{p}<$ $0.001]$, right atrial pressure (RAP) $[12 \pm 6$ to $8 \pm 5$
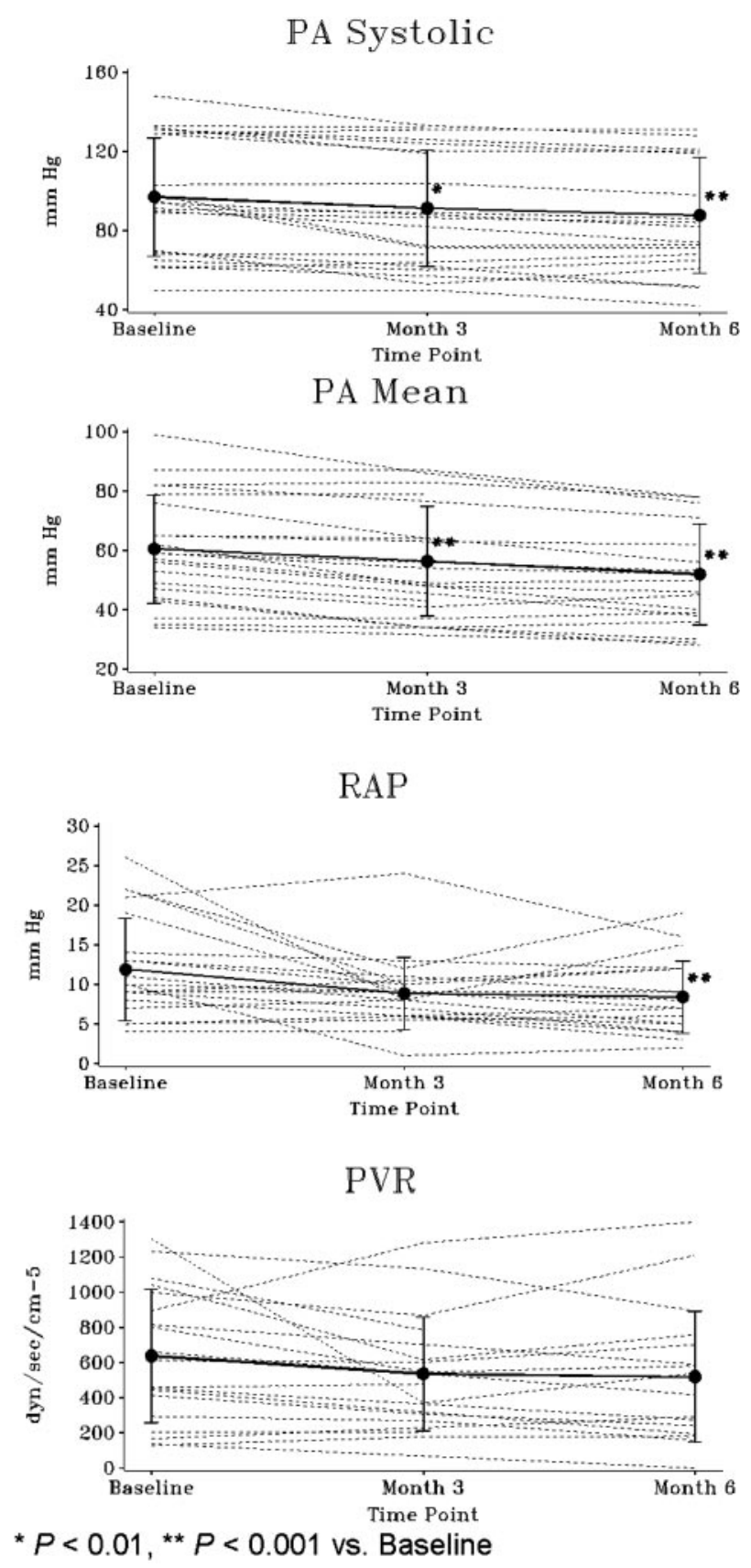

Figure 1. Hemodynamic changes at 3, 6, and 12 months after the initiation of bosentan treatment. The data represent each patient, with mean $\pm \mathrm{SD}$ values highlighted. $\mathrm{PA}$ systolic $=\mathrm{sPAP}$; PA mean $=\operatorname{mPAP} ; *=\mathrm{p}<0.01$ from baseline; $* *=\mathrm{p}<0.001$ from baseline. 
Table 2-Baseline Hemodynamics and Effects of Bosentan Over Time*

\begin{tabular}{lcccc}
\hline \hline \multicolumn{1}{c}{ Variables } & $\mathrm{N}^{2}$ & Baseline & $3 \mathrm{mo}$ & $6 \mathrm{mo}$ \\
\hline $\mathrm{MAP}, \mathrm{mm} \mathrm{Hg}$ & 21 & $95 \pm 15$ & $92 \pm 13$ & $91 \pm 14$ \\
$\mathrm{SPAP}, \mathrm{mm} \mathrm{Hg}$ & 21 & $97 \pm 30$ & $91 \pm 29 \dagger$ & $88 \pm 29+$ \\
$\mathrm{MPAP}, \mathrm{mm} \mathrm{Hg}$ & 21 & $60 \pm 18$ & $56 \pm 18+$ & $52 \pm 17+$ \\
$\mathrm{PVR}, \mathrm{dyne} \cdot \mathrm{s} \cdot \mathrm{cm}^{-5}$ & 19 & $638 \pm 380$ & $536 \pm 323 \S$ & $521 \pm 371 \S$ \\
$\mathrm{CI}, \mathrm{L} / \mathrm{min} / \mathrm{m}^{2}$ & 21 & $3.6 \pm 1.3$ & $3.9 \pm 1.4$ & $3.7 \pm 1.5$ \\
$\mathrm{RAP}, \mathrm{mm} \mathrm{Hg}$ & 21 & $12 \pm 6$ & $9 \pm 5 \S$ & $8 \pm 5+$ \\
$\mathrm{TPR}, \mathrm{mm} \mathrm{Hg} / \mathrm{L} / \mathrm{min}$ & 20 & $908 \pm 406$ & $766 \pm 386 \dagger$ & $749 \pm 451 \S$ \\
PCWP, $\mathrm{mm} \mathrm{Hg}$ & 20 & $15 \pm 5$ & $12 \pm 4 \uparrow$ & $14 \pm 6$ \\
\hline
\end{tabular}

*Values are given as the mean \pm SD. The number of subjects in each category differ because subjects who were either missing baseline values or missing both follow-up values were excluded from the analysis. $\mathrm{MAP}=$ mean arterial pressure; $\mathrm{TPR}=$ total pulmonary resistance; PCWP $=$ pulmonary capillary wedge pressure.

$\uparrow \mathrm{p} \leq 0.01$ from baseline values.

$+\mathrm{t} \leq 0.001$ from baseline values.

$\$ p<0.05$ from baseline values.

mm Hg; $\mathrm{p}<0.001$ ], PVR (663 \pm 386 to $504 \pm 307$ dyne $\cdot \mathrm{s} \cdot \mathrm{cm}^{-5} ; \mathrm{p}<0.01$ ), and pulmonary capillary wedge pressure $(15 \pm 5$ to $11 \pm 3 \mathrm{~mm} \mathrm{Hg}$; $\mathrm{p} \leq 0.001$ ). For all except RAP, bosentan therapy appeared to exhibit its greatest incremental effect, depending on the hemodynamic property viewed, in the first 3 to 6 months of therapy, with some additional improvements up to 12 months. For example, the greatest incremental benefit in PVR was noted in the first 3 months of bosentan therapy (a reduction of 99 dyne $\cdot \mathrm{s} \cdot \mathrm{cm}^{-5}$ from $663 \pm 386$ to $564 \pm 343 ; \mathrm{p}=0.03)$. After the first 3 months, slight additional reductions were observed (at 3 to 6 months, -18 dyne $\cdot \mathrm{s} \cdot \mathrm{cm}^{-5}$; at 6 to 12 months, -42 dyne $\cdot \mathrm{s} \cdot \mathrm{cm}^{-5}$ ). There were no significant changes in cardiac index $(\mathrm{CI})$, systemic vascular resistance, or mean arterial pressure. The changes in hemodynamics were independent of type, size, or patency of defect.

\section{Exercise Capacity, Borg Dyspnea Index, and NYHA Functional Class}

Complete data were available at 12 months for these parameters in all patients except for those who discontinued bosentan therapy for reasons of tolerability. Slight improvements in exercise capacity were suggested after 3 months of bosentan treatment, though these improvements did not reach statistical significance. These gradual improvements continued over the 12-month study period. At 12 months, there was a positive mean change of $31 \pm 67 \mathrm{~m}(\mathrm{p}=0.05)$ in the distance covered in a 6 -min walk test. There were no significant changes in the Borg dyspnea index after 12 months of bosentan treatment $(\mathrm{p}=0.57)$. There were also no significant changes in right ventricular end-diastolic diameter or ejection fraction by echocardiography at 3, 6, or 12 months.

At the start of the study, $4 \%$ of patients belonged to NYHA functional class IV, $79 \%$ to class III, $17 \%$ to class II, and none to class I (Fig 2). After 3 months, there was a substantial increase in the number of patients in NYHA functional class II $(42 \%, \mathrm{p}=0.02)$ and a decrease in NYHA functional class III $(58 \%)$. By the conclusion of the study, there were $29 \%$ of patients in NYHA functional class III, $54 \%$ in class II, and $17 \%$ in class I. Overall, 7 of the 24 patients stayed in the same NYHA functional class from baseline to 12 months, the condition of 1 patient worsened, and the conditions of 16 patients improved $(\mathrm{p}<0.001)$. The changes in NYHA functional class were independent of type, size, or patency of defect.

\section{Tolerability}

Three patients (12\%) reported adverse events associated with bosentan treatment. One patient discontinued therapy prematurely due to increased liver enzyme levels within the first 2 months of therapy. Two additional patients discontinued therapy after 3 months (one patient each at 6 and 9 months) as a result of increased liver enzyme levels. In these three patients, complete resolution of these changes took place with the discontinuation of bosentan therapy.

There were no deaths or hospitalizations for the overall population. Importantly, no worsening of systemic resting or exercise-induced hypoxemia (ie, arterial oxygen saturation) or evidence of volume overload requiring an adjustment in diuretic dosage

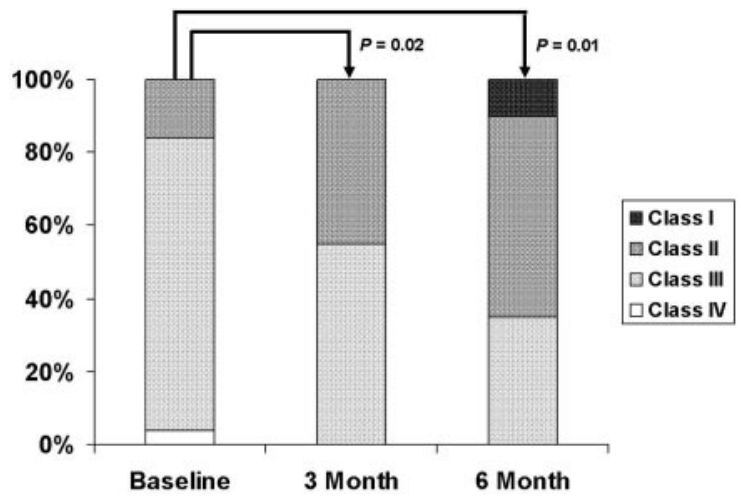

FIGURE 2. Changes in the distribution of study participants in NYHA functional class while undergoing bosentan treatment. Categorization into NYHA functional classes I (0\%), II (16\%), III $(79 \%)$, and IV (4\%) was determined at baseline, and was assessed again at 3,6, and 12 months after the initiation of the study. $\mathrm{p}=0.02$ from baseline at 3 months; $\mathrm{p}=0.009$ from baseline at 6 months; $\mathrm{p}<0.001$ from baseline at 12 months. 
was noted. There were also no significant changes in serum sodium, creatinine level, or weight. No initiation of epoprostenol was necessary. Three patients at their request were weaned from treprostinil but did not discontinue therapy between 5 and 6 months after therapy initiation in light of improved symptoms and intolerable treprostinil site pain.

\section{DISCUSSION}

The functional morbidity associated with severe $\mathrm{PAH}$ in patients with CHD, particularly those with Eisenmenger syndrome is considerable. Although the associated mortality is not as high as in other forms of PAH, it is noteworthy. Until recently, lung or heart-lung transplantation was the only hope for improved functional capacity and longer survival time in those patients with end-stage disease. Unfortunately, these forms of transplantation are associated with considerable morbidity and mortality. Patients with Eisenmenger syndrome undergoing transplantation experience dramatically higher perioperative mortality, the lowest 1-month survival rate, and poorer 1-year and 5-year survival rates compared to other lung transplant recipients. ${ }^{19}$ Additional mortality and morbidity associated with allograft coronary artery disease $\mathrm{e}^{20}$ and differential heart/lung rejection may also occur following transplantation, and may limit functional improvement and survival for these patients. ${ }^{21}$ The scarcity of donor organs is also problematic, especially with heart/lung transplantation, and may entail a waiting time in excess of 2 years. $^{22}$ In light of these shortcomings, what is needed are advanced medical therapies that have the ability to stabilize the hemodynamic profiles of potential transplant candidates and to extend the margin of time available for locating suitable organs, if not to reduce the necessity of organ transplantation altogether.

Several therapeutic agents are now available for the treatment of $\mathrm{PAH}$ that may improve functional capacity in patients with PAH related to CHD and may potentially postpone or obviate the need for undergoing transplantation. These agents include bosentan, epoprostenol, and treprostinil. Long-term prostacyclin therapy has been found to improve hemodynamics and quality of life in patients ranging in age from 2 to 51 years with congenital heart defects. ${ }^{9}$ These investigators noted that prostacyclin therapy did not result in a significant increase in exercise capacity as measured by the 6-min walk test, a finding that is similar to that of the present study. Since the 6-min walk test is a reflection of oxygen uptake, ${ }^{23}$ a surrogate of cardiac output, and knowing that patients with congenital heart defects usually present with preserved CIs, it is not surprising that changes in exercise capacity, particularly in the small cohort of patients in the present study, did not quite reach statistical significance $(\mathrm{p}=0.05)$. Indeed, in this study the mean baseline CI was preserved at $3.6 \pm 1.3 \mathrm{~L} / \mathrm{min} / \mathrm{m}^{2}$.

Improvements were noted in hemodynamics and functional capacity in PAH patients who had been treated with treprostinil. ${ }^{\text {Th }}$ This study included patients with CHD and noted no difference in treatment effects by diagnosis. Despite the potential functional improvements with epoprostenol and treprostinil, several notable limitations are associated with their use. Epoprostenol therapy requires a specialized delivery system to administer a continuous IV infusion via a semipermanent central venous catheter. This system is bulky and inconvenient to the patient, and even a transient interruption in the flow may result in life-threatening rebound pulmonary hypertension. ${ }^{24}$ More important, however, is the morbidity and mortality associated with a central venous catheter, which can range from the minor tunnel infections to thromboembolic events to potentially fatal sepsis. ${ }^{24-26}$ Furthermore, the side effects associated with epoprostenol treatment are often severe, and tolerance to the drug may develop. ${ }^{24,27}$ Treprostinil therapy is also administered as a continuous infusion, albeit subcutaneously, with the requirement of an external pump. Although this delivery system is far less cumbersome to the patient, its subcutaneous administration is often associated with severe site pain, which has led to an unreasonably high premature discontinuation rate. ${ }^{8}$ Due to these serious drawbacks, alternative treatments are necessary.

Bosentan therapy was demonstrated to be effective in improving functional capacity and cardiopulmonary hemodynamics with a significant reduction in PVR and mPAP in patients with primary pulmonary hypertension and other forms of PAH. ${ }^{17,28}$ The large published trial ${ }^{28}$ with bosentan in $\mathrm{PAH}$ patients did not, however, include patients with CHD. In light of the inherent differences in disease substrate between these patients and other patients with PAH, the efficacy of bosentan in this population cannot be inferred. The results of some studies have suggested that ET-1 plays a role in the development and severity of PAH in CHD patients ${ }^{11,29}$ and that specific antagonism therapy may be efficacious in its treatment. ${ }^{18}$ Using an animal model of systemic-topulmonary shunting similar to that found in some patients with CHD and $\mathrm{PAH}$, bosentan was found to prevent the development of overcirculation-induced PAH. ${ }^{30}$ Similarly, in a small study ${ }^{18}$ in nine patients with Eisenmenger syndrome who were treated with bosentan and were followed up for a mean duration 
of 9 months, six of nine patients $(67 \%)$ had an improvement in NYHA classification of more than one grade $(p=0.03)$. Mean oxygen saturation levels also increased from $79 \pm 5$ to $88 \pm 6 \%(\mathrm{p}=0.03)$. The results of our study extend this observation in the long term in a larger cohort of patients with CHD with PAH. In the present study, bosentan therapy significantly reduced RAP and mPAP, two hemodynamic parameters that are closely associated with survival in other forms of $\mathrm{PAH}, 31,32$ and it did so with few adverse events, particularly with no evidence of systemic desaturation or worsening volume overload. It is unclear why saturations did not similarly increase in our study as in the study by Christensen et al, ${ }^{18}$ but may reflect the low number of patient observations obtained in this earlier investigation. These results compare favorably with those of the long-term use of epoprostenol for the treatment of pulmonary hypertension associated with congenital heart defects ${ }^{9}$ and are not likely to be a placebo effect, given the observed objective changes in hemodynamics and the longer than usual duration of this observation period ( 52 weeks) compared to the length of many studies of 12 to 16 weeks that have been conducted in PAH patients. ${ }^{8,17,28}$

Bosentan appears to be well-tolerated in this patient population. There were no fatalities or hospitalizations during the course of the study. Indeed, in light of the significant improvement in functional capacity, no patients required referral for heart/lung transplantation or rescue epoprostenol therapy. The percentage of patients in whom LFT abnormalities developed (12\%) was similar to that in other classes of PAH patients treated with bosentan. ${ }^{28,33}$ This rate of LFT changes emphasizes the need for the routine surveillance of patients receiving bosentan and is a recognized shortcoming of this class of agent. In addition, these results suggest that the greatest magnitude of improvement with bosentan is within the first 3 to 6 months, although continued improvements, albeit mild, are seen for up to 12 months. This feature may be useful clinically when making a decision regarding lack of response to treatment, such that patients who have not suitably responded to therapy by 6 months could be moved to alternative treatments. In addition, further study is needed to determine the long-term effects of concomitant bosentan and prostacyclin therapy for PAH, including whether the addition of bosentan may lead to a reduction or an elimination of prostacyclin therapy. Two studies have demonstrated successful weaning from epoprostenol with a transition to bosentan oral therapy in adults ${ }^{34}$ and children, ${ }^{35}$ with no adverse effects on hemodynamic parameters. Indeed, in our study, none of the three patients who were weaned from treprostinil experienced any worsening of clinical symptoms.

The open-label nature of this study, the small number of patients and the lack of complete data on all efficacy parameters in this analysis needs to be emphasized. We acknowledge these obvious limitations and concede that these likely limited the robustness of our results, particularly for the 6-min walk test and hemodynamics. However, the observation of a sustained improvement in hemodynamics and well-being in these chronically ill patients over this extended time frame is encouraging, is consistent with that seen with epoprostenol therapy, ${ }^{9}$ and deserves further study. We acknowledge that a potential interaction, favorable or not, may exist and may have affected treatment efficacy in the patients who had been treated with combinations of treprostinil and bosentan. Subanalyses of efficacy end points (ie, NYHA functional class, 6-min walk distance, Borg index, hemodynamics, and laboratory test results) did not demonstrate any difference in efficacy after 12 months between the group of patients receiving combination therapy and the group receiving bosentan alone. We recognize, however, that the impact of these analyses must be weighed with caution because of the small patient numbers in each of these groups. Again, we stress that further study is needed to determine the longterm effects of concomitant bosentan and prostacyclin therapy for PAH. Additionally, the decision to carry the last observation forward to address the issue of missing data may be considered a limitation. However, this technique is commonly used and often has been shown to provide conservative estimates of the effect of interest.36,37 Furthermore, the last observation carried forward may underestimate the true variability in the data, ${ }^{37}$ a problem that can be overcome with the use of more complex analytic techniques. ${ }^{38}$ To address the robustness of our findings, we implemented multiple imputations for several outcomes of interest and obtained the same results. Therefore, we report only the results from the last-observation-carried-forward analysis.

This 12-month study provides follow-up data for the longest time period on bosentan therapy in adults with CHD to date and demonstrates that therapy with the oral ET receptor antagonist bosentan may significantly improve the overall cardiopulmonary hemodynamics and NYHA functional class in patients with this form of PAH. Further investigations are warranted to examine the effects of bosentan on a larger patient population, as well as to understand whether long-term bosentan therapy can reduce the use of concomitant prostanoid therapy. 
ACKNOWLEDGMENT: The authors would like to acknowledge the useful and invaluable insights, comments, and suggestions along with the other contributions made by Mark Law, MD, and Krys L. Thomas, RN, BSN.

\section{REFERENCES}

1 Young D, Mark H. Fate of the patient with the Eisenmenger syndrome. Am J Cardiol 1971; 28:658-669

2 Saha A, Balakrishnan KG, Jaiswal PK, et al. Prognosis for patients with Eisenmenger syndrome of various aetiology. Int J Cardiol 1994; 45:199-207

3 Berman EB, Barst RJ. Eisenmenger's syndrome: current management. Prog Cardiovasc Dis 2002; 45:129-138

4 Silversides CK, Granton JT, Konen E, et al. Pulmonary thrombosis in adults with Eisenmenger syndrome. J Am Coll Cardiol 2003; 42:1982-1987

5 Somerville J, Aaron MF. How to manage the Eisenmenger syndrome. Int J Cardiol 1998; 63:1-8

6 Ueno T, Smith JA, Snell GI, et al. Bilateral sequential single lung transplantation for pulmonary hypertension and Eisenmenger's syndrome. Ann Thorac Surg 2000; 69:381-387

7 Edwards LB, Keck BM. Thoracic organ transplantation in the US. Clin Transpl 2002;29-40

8 Simonneau G, Barst RJ, Galie N, et al. Continuous subcutaneous infusion of treprostinil, a prostacyclin analogue, in patients with pulmonary arterial hypertension: a doubleblind, randomized, placebo-controlled trial. Am J Respir Crit Care Med 2002; 165:800-804

9 Rosenzweig EB, Kerstein D, Barst RJ. Long-term prostacyclin for pulmonary hypertension with associated congenital heart defects. Circulation 1999; 99:1858-1865

10 Giaid A, Yanagisawa M, Langleben D, et al. Expression of endothelin-1 in the lungs of patients with pulmonary hypertension. N Engl J Med 1993; 328:1732-1739

11 Yoshibayashi M, Nishioka K, Nakao K, et al. Plasma endothelin concentrations in patients with pulmonary hypertension associated with congenital heart defects: evidence for increased production of endothelin in pulmonary circulation. Circulation 1991; 84:2280-2285

12 Rubens C, Ewert R, Halank M, et al. Big endothelin-1 and endothelin-1 plasma levels are correlated with the severity of primary pulmonary hypertension. Chest 2001; 120:1562-1569

13 US Food and Drug Administration. FDA approves first oral medication for pulmonary arterial hypertension. Rockville, MD: US Food and Drug Administration, 2001

14 Verma S, Li SH, Badiwala MV, et al. Endothelin antagonism and interleukin-6 inhibition attenuate the proatherogenic effects of C-reactive protein. Circulation 2002; 105:18901896

15 Porter KE, Olojugba DH, Masood I, et al. Endothelin-B receptors mediate intimal hyperplasia in an organ culture of human saphenous vein. J Vasc Surg 1998; 28:695-701

16 Mulder P, Richard V, Derumeaux G, et al. Role of endogenous endothelin in chronic heart failure: effect of long-term treatment with an endothelin antagonist on survival, hemodynamics, and cardiac remodeling. Circulation 1997; 96: 1976-1982

17 Channick RN, Simonneau G, Sitbon O, et al. Effects of the dual endothelin-receptor antagonist bosentan in patients with pulmonary hypertension: a randomised placebo-controlled study. Lancet 2001; 358:1119-1123

18 Christensen DD, McConnell ME, Book WM, et al. Initial experience with bosentan therapy in patients with the Eisenmenger syndrome. Am J Cardiol 2004; 94:261-263
19 Trulock EP. Lung transplantation for primary pulmonary hypertension. Clin Chest Med 2001; 22:583-593

20 Marelli D, Laks H, Kobashigawa JA, et al. Seventeen-year experience with 1,083 heart transplants at a single institution. Ann Thorac Surg 2002; 74:1558-1566

21 Trulock EP, Edwards LB, Taylor DO, et al. The Registry of the International Society for Heart and Lung Transplantation: twentieth official adult lung and heart-lung transplant report; 2003. J Heart Lung Transplant 2003; 22:625-635

22 United Network for Organ Sharing. UNOS Scientific Registry Data as of September 5: 2. Patient survival rates at three months and at one, three and five years; Table 84-Lung Transplants. Available at: www.UNOS.org. Accessed April 12, 2000

23 Solway S, Brooks D, Lacasse Y, et al. A qualitative systematic overview of the measurement properties of functional walk tests used in the cardiorespiratory domain. Chest 2001; 119:256-270

24 McLaughlin VV, Shillington A, Rich S. Survival in primary pulmonary hypertension: the impact of epoprostenol therapy. Circulation 2002; 106:1477-1482

25 Prandoni P, Polistena E, Bernardi A, et al. Upper-extremity deep vein thrombosis. Risk factors, diagnosis, and complications. Arch Intern Med 1997; 157:57-62

26 Timsit JF, Farkas JC, Boyer JM, et al. Central vein catheterrelated thrombosis in intensive care patients: incidence, risks factors, and relationship with catheter-related sepsis. Chest 1998; 114:207-213

27 Rubin LJ, Mendoza J, Hood M, et al. Treatment of primary pulmonary hypertension with continuous intravenous prostacyclin (epoprostenol). Results of a randomized trial. Ann Intern Med 1990; 112:485-491

28 Rubin LJ, Badesch DB, Barst RJ, et al. Bosentan therapy for pulmonary arterial hypertension. N Engl J Med 2002; 346: 896-903

29 Cacoub P, Dorent R, Maistre G, et al. Endothelin-1 in primary pulmonary hypertension and the Eisenmenger syndrome. Am J Cardiol 1993; 71:448-450

30 Rondelet B, Kerbaul F, Motte S, et al. Bosentan for the prevention of overcirculation-induced experimental pulmonary arterial hypertension. Circulation 2003; 107:1329-1335

31 Okada O, Tanabe N, Yasuda J, et al. Prediction of life expectancy in patients with primary pulmonary hypertension: a retrospective nationwide survey from 1980-1990. Intern Med 1999; 38:12-16

32 D'Alonzo GE, Barst RJ, Ayres SM, et al. Survival in patients with primary pulmonary hypertension: results from a national prospective registry. Ann Intern Med 1991; 115:343-349

33 Cohen H, Chahinfe C, Hui A, et al. Bosentan therapy for pulmonary arterial hypertension. Am J Health Syst Pharm 2004; 61:1107-1119

34 Kim NH, Channick RN, Rubin LJ. Successful withdrawal of long-term epoprostenol therapy for pulmonary arterial hypertension. Chest 2003; 124:1612-1615

35 Ivy DD, Doran A, Claussen L, et al. Weaning and discontinuation of epoprostenol in children with idiopathic pulmonary arterial hypertension receiving concomitant bosentan. Am J Cardiol 2004; 93:943-946

36 Liu G, Gould AL. Comparison of alternative strategies for analysis of longitudinal trials with dropouts. J Biopharm Stat 2002; 12:207-226

37 Gadbury GL, Coffey CS, Allison DB. Modern statistical methods for handling missing repeated measurements in obesity trial data: beyond LOCF. Obes Rev 2003; 4:175-184

38 Rubin DB. Multiple imputation for nonresponse in surves. New York, NY: John Wiley \& Sons, 1987 


\section{Efficacy of Bosentan in a Small Cohort of Adult Patients With Pulmonary Arterial Hypertension Related to Congenital Heart Disease}

Raymond L. Benza, Barry K. Rayburn, Jose A. Tallaj, Christopher S. Coffey, Laura

J. Pinderski, Salpy V. Pamoukian and Robert C. Bourge

Chest 2006;129;1009-1015

DOI: $10.1378 /$ chest.129.4.1009

This information is current as of April 12, 2006

Updated Information \& Services

References

Permissions \& Licensing

Reprints

Email alerting service

Images in PowerPoint format
Updated information and services, including high-resolution figures, can be found at:

http://www.chestjournal.org/cgi/content/full/129/4/1009

This article cites 34 articles, 17 of which you can access for free at:

http://www.chestjournal.org/cgi/content/full/129/4/1009\#BIB L

Information about reproducing this article in parts (figures, tables) or in its entirety can be found online at: http://www.chestjournal.org/misc/reprints.shtml

Information about ordering reprints can be found online: http://www.chestjournal.org/misc/reprints.shtml

Receive free email alerts when new articles cite this article sign up in the box at the top right corner of the online article.

Figures that appear in CHEST articles can be downloaded for teaching purposes in PowerPoint slide format. See any online article figure for directions.

$\begin{array}{llllllllll}\mathrm{P} & \mathrm{H} & \mathrm{Y} & \mathrm{S} & \mathrm{I} & \mathrm{C} & \mathrm{I} & \mathrm{A} & \mathrm{N} & \mathrm{S}\end{array}$

